\title{
Por los ciclos de los ciclos... De la universidad al terreno
}

\author{
Aldana Neme, ${ }^{1}$ \\ Sonia Olmedo ${ }^{2}$ \\ Silvia Gabriela Vázquez ${ }^{3}$ \\ olmedosonia86@gmail.com \\ Rec. 15/11/2017, Apr. 22/03/2018
}

Los ciclos sin fin de la idea y la acción, inversión sin fin, experimento sin fin, traen conocimiento del movimiento, pero no de la quietud; conocimiento de la palabra, pero no del silencio; conocimiento de las palabras, e ignorancia de la palabra. Todo nuestro conocimiento nos trae más cerca a nuestra ignorancia.

T.S. Eliot, Coros de la roca.

Elegir una carrera. Idealizarla. Proyectarse. Probar y seguir. Probar o cambiar. Atravesar todas las vicisitudes que se encuentran en ese camino. Frustrarse. Demorarse, desenamorarse y desmoronarse. Reconstruirse y enamorarse de vuelta. Proyectarse otra vez. Re-elegirla. Finalizarla. ¿Y ahora, qué?

Elegir una carrera profesional implica elegir un modo desde el cuál mirar y asomarse al mundo. Un modo de percibir, sentir, comprender y explicar una porción de la realidad. Al elegir carreras dentro de las Ciencias Sociales, se deberá asumir que se trabajará alrededor de procesos. Esta dialéctica del devenir existencial, presupone ciclos en los cuáles esos procesos comienzan, se desarrollan y llegan a su punto culmine

1 Especialista en Gestión de la Educación (Universidad Torcuato Di Tella). Psicóloga Social (Universidad CAECE). Coordinadora, docente y tutora en Escuela de Psicología Social del Sur. Coordinadora de prácticas y docente titular en la materia "Nivel de prácticas III" del Instituto Universitario "Madres de Plaza de Mayo".

2 Psicóloga (Universidad de Buenos Aires).

3 Psicopedagoga. Directora de la Cátedra de Responsabilidad Social Universitaria UdeMM. Sec. Académica de la Red Latinoamericana de Orientadores. 
para dar inicio a un nuevo ciclo que, por supuesto, está entramado con los demás. En la idea de "carrera" postulada en este artículo, la trayectoria que se recorre no es lineal, siempre hacia adelante y en competencia con otros, sino espiralada, con instancias ascendentes, descendentes, momentos de estancamiento y acople con otros que, lejos de competir por posiciones a ganar, son nodos clave para ejercer la profesión. Se debe reconocer y celebrar que las construcciones son colectivas. No es posible concebir otro modo de desarrollar las profesiones enmarcadas en las Ciencias Sociales.

Se identifican, así, cuatro ciclos en la construcción del devenir y el perfil del profesional que desee desempeñarse dentro de las Ciencias Sociales. Estos comienzan luego del feliz hito de graduación y la ineludible pregunta: ¿y ahora qué?

Por supuesto, estos ciclos están interconectados entre sí, y el pasaje a un nuevo ciclo incluye algunos hitos que se describen a continuación en relación a dimensiones tales como la red de contactos, las elecciones y las posibilidades de formación.

\section{Ciclo inicial de transición e indecisión}

[...] las predisposiciones e improntas culturales y sociales, las oportunidades familiares y educativas que ofrecen terrenos aptos para que algunas aptitudes germinen y otras no.

\section{Marina Müller, Formación Docente y Psicopedagogía.}

Es la primera etapa que se atraviesa luego de recibirse. Está caracterizada en general por incertidumbre, desconcierto e indecisión en relación al campo al que el reciente profesional desea incorporarse. Puede resultar una etapa angustiante dado que es la de "puesta en marcha" de los primeros pasos profesionales, en el que se tiene que activar la propia red de contactos para lograr la inserción profesional. En muchas ocasiones esta red existe aunque no está visibilizada ni explotada. En esta fase se invierte energía en la búsqueda de un campo profesional en el cuál insertarse y las respuestas, que muchas veces no llegan, generan gran ansiedad.

En esta etapa se suele oscilar entre la idealización por la profesión y la frustración por la demora de propuestas laborales concretas.

En relación con las elecciones, aparecen dificultades para comprender los límites profesionales y el entusiasmo ante un posible proyecto, lo cual lleva a involucrarse en planes que requieren competencias por fuera de los límites del campo propio o de una expertise mayor.

Es necesario hacer el duelo por aquellos proyectos que, por el momento, no podrán llevarse a cabo y aceptar las propias limitaciones.

Se puede mencionar que en esta fase comienza a construirse, a nivel profesional, lo que Inés Temple en su libro "Usted SA" denomina "la empleabilidad", entendiéndola como las habilidades, capacidades y competencias que permitan encontrar o mantener un empleo. Señala también que esas capacidades abarcan los aspectos individuales que hacen a mejorar competencias, los vínculos y contactos necesarios para mantener sostener y tener capacidad de decisión sobre los propios proyectos. Es por ello que, en este ciclo, es de vital importancia conectarse con ex compañeros de cursada y antiguos docentes de la carrera. 
La incertidumbre y la indecisión son las reinas de esta etapa en las que, en ocasiones, aparece la tendencia compulsiva a la formación, por lo que los profesionales toman cursos, seminarios o posgrados. Con ello buscan seguir formándose y adquirir una sensación de mayor seguridad en lugar de salir al campo profesional y luego formarse en lo que requieran para hacer mejor lo que ya hacen.

En relación a la formación, en esta fase se pueden cometer errores estratégicos y comenzar posgrados cuando aún no se recorrió lo suficiente el campo profesional para construir expertise en determinados temas que luego orienten la elección de este tipo de formación.

Esto último suele estar relacionado con la representación social que como estudiantes de grado o terciarios se puede tener con respecto a la terminación de la carrera, donde supuestamente se contará con todas las respuestas. Puede ser grande la sorpresa cuando, al finalizar el recorrido académico formal, se encuentran con nuevas preguntas.

En otros campos, como las ciencias exactas, puede ser más factible finalizar el recorrido de formación con certezas, pero el campo de las Ciencias Sociales marca un quiebre al plantear más y más interrogantes hacia el final de la universidad.

Con el tiempo quizá puede comprenderse e incluso valorarse esta característica, pero al principio puede ser fuente de tensión, frustración y grandes dilemas para el profesional recién recibido. ¿Acaso la Universidad no brinda todas las respuestas? ¿Acaso después de tantos años de estudios el egresado no cuenta con plena seguridad en cuanto a su profesión y sus incumbencias? Pues no, y esto es usual en el campo de las Ciencias Sociales. Las preguntas serán mejor motor que las certezas para iniciar la práctica profesional.

\section{Ciclo generalista e inespecífico}

Planificar: concebir el futuro deseado así como los medios reales para alcanzarlo.

Russel Ackoff, Science in the Systems Age.

Es una fase de exploración, donde el profesional puede colaborar en proyectos muy disímiles entre sí, ya que es la etapa de la formación de la experiencia en la que aún no se puede definir un núcleo de expertise. Suelen aparecer dificultades para decir "no", debidas al costo que implicó atravesar la fase anterior de transición e indecisión. En este sentido, esta etapa muchas veces convive con otro empleo formal que el profesional aún no ha abandonado por no sentirse lo suficientemente fortalecido para dedicarse de lleno a su carrera. No obstante, se detectan -en esta etapa- ciertos rasgos idealistas acerca de las posibilidades profesionales en el que las expresiones de deseo en relación a la generación de proyectos y emprendimientos propios crecen con llamativa euforia.

Aquí todavía no se evalúa con detalle qué emprender y con quién, porque aparece cierta obnubilación por la posibilidad real de dejar el empleo habitual para volcarse de lleno a la profesión.

En la inserción a nivel concreto, comienza a tejerse la red profesional y se visibiliza con más claridad cuáles son los nodos de la propia red que se pueden activar. En 
relación con esto último, en esta fase aparece la búsqueda y la inserción concreta en proyectos ya gestados por otros, talleres, espacios de ayudantías, voluntariados, participación en equipos de investigación, exposiciones de trabajos previos en congresos, entre otros. Se dan los primeros pasos en el campo profesional, a veces, de la mano de un colega de mayor expertise que detectó cierto potencial y abrió posibilidades como las ya mencionadas. Se pagan los primeros derechos de piso como "costo de ingreso" a algunos espacios profesionales.

Para atravesar esta etapa se necesita mucha humildad, organización y perseverancia, de modo que se puedan tomar decisiones estratégicas en relación al desarrollo de la carrera profesional, reparando en que la misma no sólo se construye a través de las experiencias, sino también a partir de los "no". Esta humildad para reconocer las propias limitaciones éticas, de incumbencias y técnicas deberá estar, por supuesto, presente en todas las fases.

Al ser una etapa generalista, también la búsqueda de formaciones suele transitar este carril, dado que se está explorando y recortando las temáticas de interés.

Poco a poco, se irá acotando el área específica del interés profesional que en la etapa anterior resultaba demasiado amplia e incluso difusa y hacia allí se espera que vayan dirigidos los proyectos de formación de posgrado o las nuevas búsquedas laborales que darán lugar al ciclo siguiente.

\section{Ciclo de desarrollo y expansión}

Las personas con más éxito del mundo son las que tienen en cuenta el bien mayor de todos los implicados [...] les encanta su trabajo y por eso están continuamente inspirados y creativos.

David R. Hawkins, El poder frente a la fuerza.

Como se mencionó, luego de la exploración del ciclo anterior se comienzan a recortar las temáticas de interés y se va ganando experiencia en ese campo. El profesional ya no es un reciente graduado y ya no se percibe a sí mismo como de "amplio espectro", sino que puede reconocer que, más allá de su incumbencia, se ha formado y tiene experiencia medianamente sólida en ciertos campos específicos, lo cual le permite enriquecer los proyectos en los que se involucre.

Aquí aparecen criterios más definidos y realistas a la hora de elegir entre las propuestas concretas que le llegan, ante las búsquedas que emprenderá e incluso en los propios proyectos que podría planificar. Se espera entonces que estos proyectos estén dentro de los campos en los que el profesional se ha desarrollado y allí donde sienta que puede aportar valor. No sólo se trata de poner en juego la vocación, sino también de aportar algo a los demás. Eso es lo que otorgará el verdadero sentido a la tarea.

En esta etapa algunos ya han abandonado sus empleos tradicionales y otros mantienen ambas estructuras en paralelo, situación que en algún momento puede transformarse en una tensión a resolver. En este sentido, aparecen las primeras convocatorias reconociendo al profesional como aquel idóneo que trabaja en un tema específico. Es por ello 
que, poco a poco, empieza a hacerse visible con más fuerza dentro del campo profesional el nombre propio como una marca personal que gestionará y desarrollará con esmero.

A nivel de publicaciones, en esta etapa suelen aparecer las primeras escrituras de artículos que aporten visibilidad y alcance cada vez más masivo, en general junto a otros colegas con los que se trabaja e incluso aquellos "mentores" que han brindado las primeras oportunidades. Se va delineando una estrategia de posicionamiento que acompañe el ciclo de expansión y se asume -a veces con un poco de resistencias- que el propio nombre es y será una marca en sí misma.

En relación a la formación, en esta fase se suelen tomar cursos y seminarios sobre la temática que se está trabajando y sobre otras adyacentes. A diferencia de las etapas anteriores, tal vez ya no se dispone de tanto tiempo para formarse; por ello, el profesional escoge, a conciencia, los espacios de formación en los cuales involucrarse. Es la etapa ideal para elegir estudios que retroalimenten, enriquezcan la experiencia adquirida y aporten el valor de un título de posgrado al creciente CV.

\section{Ciclo de apogeo y profesionalización}

Es completamente cierto, y toda la experiencia histórica lo confirma, que no se hubiera logrado lo posible si en el mundo una y otra vez no se hubiese intentado lo imposible.

Max Weber, La política como profesión.

Es la etapa de instalación de la marca personal y la consagración profesional. Esta fase tiene una fuerte raigambre en el recorrido que se ha transitado y en las decisiones estratégicas tomadas en relación a:

- La gestión de la propia red de contactos.

- Las propuestas a las que, por ética, se le ha dicho "no".

- La identificación del plus de valor concreto que cada profesional puede apor tar según sus áreas de interés, actualización y formación continua.

En esta instancia el profesional ya se distingue de otros colegas por su huella o marca personal y cuidará de ella con dedicación, dado que el sustento de esta consagración en el campo tiene dos fuertes raíces: prestigio y reputación. En este sentido, es posible que el profesional sea visto por sus colegas con admiración y que éstos lo tomen como referente o voz autorizada en determinadas temáticas.

Aquí se suelen escoger sólo proyectos relacionados con la propia expertise y se cuenta con publicaciones propias (artículos, libros, página web profesional). El profesional es convocado desde diversos espacios como expositor y para participar en mesas de debate, brindar conferencias o hacerse cargo de cátedras a nivel terciario/universitario cuyos núcleos de contenido están relacionados con su experiencia. Pasa a ser visto por sus alumnos y colegas recién recibidos como un mentor y un nodo importante dentro de la red profesional que ellos recién están comenzando a construir. 
La articulación de la propia práctica, los trabajos realizados para sus estudios de posgrado y el nivel de expertise adquirido, hace que sea el tiempo de publicaciones varias, muchas de ellas por motus propio y otras por convocatorias de revistas y medios distinguidos.

\section{Conclusiones}

Para finalizar, cabe destacar que, como se señaló al principio, estos ciclos no se recorren de manera lineal. Por el contrario, es la complejidad y ambigüedad de los procesos entramados lo que fortalece a un profesional. Como dice el conocido refrán popular: "Ningún marinero se hace experto con un mar en calma".

En este sentido, los vertiginosos cambios en los escenarios sociales, culturales, económicos y tecnológicos, hacen que los profesionales no se construyan de una vez y para siempre. Por el contrario, se sentirán interpelados en forma permanente a desarrollar nuevas competencias que les permitan abordar con mayor agudeza las problemáticas sociales. Un profesional actualizado será siempre un profesional requerido y con rasgos de empleabilidad, más allá de las vicisitudes del mercado.

No obstante, necesitará un alto grado de compromiso y de resiliencia para afrontar las crisis, obstáculos y adversidades que pudieran presentarse. Es por ello que la propuesta de cierre de este artículo es abrir la pregunta en relación al ciclo que está atravesando el lector y las decisiones estratégicas que puede tomar para orientar el rumbo hacia su proyecto profesional. No hay arribo a la costa deseada si antes no hay un mapa que establezca la posición de navegación y el posible camino a seguir.

Si cada uno de los lectores -gracias a la introspección, el vínculo con otros colegas y el autoconocimiento- logra identificar el ciclo profesional en el que está, podrá comprender que, si bien en todas las etapas hay invariables, los ciclos van cambiando...

$\mathrm{Y}$ es que la formación, interpelación, creación y resignificación profesional -tal como solía cantar Vinicius de Moraes- "não tem fim".

\section{Bibliografía}

—Ackoff, R. L. (1973) Science in the Systems Age: Beyond IE, OR, and MS. in Operations Research Quarterly, University of Pennsylvania, Philadelphia, Pennsylvania.

- Hawkins David R., (2014) El poder frente a la fuerza, Barcelona, Editorial El Grano de Mostaza.

— Müller M. (2010). Formación Docente y Psicopedagogía, Buenos Aires, Editorial Bonum.

— Neme, A. y De la Vega, F. (2011). GPS: Grupos Produciendo Sentidos. Buenos Aires. Mesa Editorial.

- Temple, I. (2015). Usted SA. Lima: Editorial Planeta.

- Vázquez, S. G. (2008). "Orientación vocacional basada en el enfoque de resiliencia”. En Modernidad, Tecnología y Sintomas contemporáneos. Asociación Argentina de Salud Mental. 
- Vázquez, S. G. (2017). Formar profesionales competentes, comprometidos y resilientes. Editorial Académica Española.

- Weber, Max; (2007) La politica como profesión, Madrid, Biblioteca Nueva. 